\title{
NEM RORTY, NEM HABERMAS, NEM MARX: POR UMA FILOSOFIA DA PRÁXIS POIÉTICO-MATERIALISTA, NÃO LINGUOCÊNTRICA
}

\author{
JOSÉ CRISÓSTOMO DE SOUZA ${ }^{1}$
}

\begin{abstract}
RESUMO: Nesse breve ensaio ofereço o esboço, condensado, de um ponto de vista práticopoiético, sensível, em filosofia, em diálogo crítico principalmente com os neo-pragmatismos linguocêntricos de Jürgen Habermas e Richard Rorty, com boa parte do pragmatismo clássico e, por fim, com o materialismo prático-dialético de Karl Marx. Faço isso com base nas noções, propostas por mim, de intencionalidade prático-sensível, de realidade e de nós próprios como atividade sensível, da ação humana como eminentemente poiética, também objetivação e apropriação, e, por conclusão, aponto para uma reconsideração do papel dos objetos nas nossa práticas, interações e mesmo auto-constituição, e faço um aceno a consequências políticas, democráticas, do referido ponto de vista.
\end{abstract}

PALAVRAS-CHAVE: intencionalidade prática sensível; atividade prático-criativa; objeto e objetivação; pragmatismo; materialismo

ABSTRACT: In this brief essay I offer the condensed outline for a practical-poietic, material, point of view in philosophy, in critical dialogue mainly with the linguocentric neo-pragmatisms of Jürgen Habermas and Richard Rorty, with part of classical pragmatism, as well as with Karl Marx's practical-dialectic materialism. To do that, I propose the notions of practical-sensible activity, of reality and ourselves as eminently sensible activity, of human action as pervasively poietic, therefore also objectification and appropriation, and, in conclusion, I point to a reconsideration of the role of objects in our practices, interactions and even self-constitution, and hint at democratic political consequences for the above mentioned point of view.

KEYWORDS: practical-sensible intentionality; practical-creative activity; object and objectification; pragmatism; materialism

\section{Apresentação}

O que ofereço aqui são alguns delineamentos para um paradigma da produção, renovado, o que chamo de um ponto de vista poiético-pragmático, ou ainda de um materialismo prático-poiético (de poiésis, produção, criação), que pode ser entendido como situado entre pragmatismo, neopragmatismo (Rorty e Habermas), hegelianismo e Marx. São delineamentos aqui apresentados muito resumidamente, junto com mais elementos apenas indicados, pois os

\footnotetext{
${ }^{1}$ Professor titular de Filosofia da Universidade Federal da Bahia (UFBA). Coordenador do Grupo de Pesquisa Poética Pragmática e membro do Centro de Estudos Dewey e Pragmatismo. Doutor em filosofia pela Universidade Estadual de Campinas (UNICAMP). E-mail: josecrisostomodesouza@gmail.com.
} 
aspectos em que se pode desdobrar a referida posição apresentam-se como muito amplos e variados. $^{2}$

Trata-se de um ponto de vista prático marcado por uma nova ênfase na dimensão material sensível, produtiva, criadora, da ação humana, e de nosso decorrente envolvimento com o mundo. Articulado por recurso a noções tais como poiesis, intencionalidade sensível significadora, noções de nós e do real como atividade sensível, do mundo como artefato, da sociedade como uma trama de práticas, relações e objetos etc. $\mathrm{O}$ que envolve como consequência a revisão e rearticulação de outras tantas noções filosóficas tradicionais como realidade, ação, representação, correspondência, fundamentação, experiência, conhecimento e normatividade. Resultando por fim em uma moldura geral que eu chamaria de um holismo materialista e histórico.

Trata-se de um ponto de vista prático-poiético, sensível, que, depois de tudo, permanece fiel entre outras coisas a certos elementos básicos do pragmatismo clássico, quiçá tirando deles novas consequências, mais espessas. Refiro-me a elementos tais como a sentença de Alexander Bain (uma crença é um hábito ou disposição de ação), a máxima peirceiana do pragmatismo (a noção de um objeto como sendo a de seus efeitos de alcance prático), como o protagorismo/humanismo de Ferdinand Schiller e William James (o rastro da serpente humana está em toda parte), como o ponto de vista do agente, de Dewey, e também sua noção alargada da experiência e do real como prática.

Fora do campo pragmatista em sentido estrito podemos ainda incluir nessa lista o elemento pragmatista de Heidegger, sua tematização, nada linguocêntrica, da Zuhandenheit, manualidade, para mim usualidade, como nosso modo de relação mais originária e básica, usuária, com as coisas, com os artefatos e com o mundo. Além de outras sugestões práticas, do Hegel da Fenomenologia do Espírito, do jovem hegelianismo posterior, construcionistas darwinianas do Nietzsche de Verdade e Mentira no Sentido Extra-Moral etc. etc. Por último, vale reconhecer as associações do referido ponto de vista com o voluntarismo e modernismo

\footnotetext{
${ }^{2}$ Para uma exposição menos resumida desse ponto de vista seria o caso de ver uma série inteira de meus materiais publicados ao longo de mais de vinte anos, que constituem seu desenvolvimento progressivo, entre os quais destaco1) o "Marx and Feuerbachian Essence", em The Left Hegelians, Cambridge U. Press, 2) "Filosofia como Coisa Civil", parte do meu livro A Filosofia entre Nós, com Janine, Porchat e Tugendhat, ed. Unijuí, 3) a introdução ao Filosofia, Racionalidade, Democracia: O Debate Rorty-Habermas, Ed. Unesp, e 4) meus materiais mais recentes publicados em Cognitio (PUC-SP) ns. 13, 16, 18: "Teses ad Marx", "O Mundo Bem Nosso", "Sobre o que Pode ou não Pode um Ponto de Vista Prático em Filosofia”. Esses últimos três constroem mais diretamente o ponto de vista aqui oferecido. São resultados que tenho ademais exposto em congressos e colóquios nacionais e internacionais. Para um panorama mais completo desse percurso de produção e diálogo que leva a minha posição própria poiético-pragmática, ver a página pessoal acadêmica www.jcrisostomodesouza.ufba.br/.
} 
filosófico francês da ação, ${ }^{3}$ com o modernismo em geral, o modernismo português de Antero de Quental, o modernismo brasileiro, em particular Oswald de Andrade e Gilberto Freyre, e o hegelianismo desenvolvimentista brasileiro, do ISEB e de Mangabeira Unger. ${ }^{4}$

Também o pragmatismo mais recente, ou neo-pragmatismo, de Rorty ou de Habermas, pós virada linguística, pretende retomar e realçar um conjunto de virtudes do pragmatismo clássico, e mais. Virtudes que podem ser condensadas nuns tantos "ismos" críticos, pósmetafísicos, revisionistas de boa parte das filosofias anteriores, mesmo as modernas, tais como: não-representacionismo, não-fundacionismo, não-transcendentalismo, não-dogmatismo, junto com, no plano prático, afirmativamente, pluralismo, ativismo, melhorismo. Tudo isso galgado pelos neo-pragmatismos recentes através de contribuições da conhecida virada linguística em proveito de um pragmatismo afastado do positivismo e de eventuais fundacionismos, menos dependente do paradigma da ciência natural, mais desembaraçadamente contextualista e histórico, mais aberto à noção de intersubjetividade e à referência permanente a práticas.

É o que encontramos em boa medida tanto nas posições de Jürgen Habermas quanto, talvez mais tipicamente, nas de Richard Rorty, não obstante as diferenças entre ambos, mesmo enquanto neo-pragmatistas. O primeiro mais peirciano, kantiano, o segundo mais deweyano, jovem-hegeliano - e transformativo. Dos dois lados, igualmente, um não-correspondentismo (quanto à concepção de verdade) e uma proposta de socialização da razão. Donde um justificacionismo epistemológico, com implicações favoráveis à solidariedade e à inclusão social e política - no lugar da noção moderna de objetividade e de razão centrada no sujeito. Ambos, então, Habermas e Rorty, como gostaríamos, intersubjetivistas, não-logocêntricos, não empiristas dogmáticos, não mentalistas cartesianos. Ao mesmo tempo, do lado de Habermas, universalismo e incondicionalismo, embora moderados, e, do lado de Rorty, mais contingência e mais criação. Vejamos isso um pouco mais de perto.

\section{Parte I - Pragmatismo romântico (Rorty) versus pragmatismo kantiano (Habermas). Ambos linguocêntricos}

Nos casos de Habermas e Rorty, temos dois filósofos neo-pragmatistas, um provindo de Marx (Habermas), outro da filosofia analítica (Rorty), embora este também de Marx se considerados seu círculo familiar e sua formação intelectual de juventude. Os dois muitas vezes pensados como antípodas um do outro, um sério e racionalista (Habermas), outro pós-moderno

\footnotetext{
${ }^{3}$ Ver, de L. Susan Stebbing, Pragmatism and French Voluntarism (Cambridge University Presse, 1914), para uma aproximação e distinção entre as duas coisas.

${ }^{4}$ De Roberto Mangabeira Unger, ver em especial The Self Awakened: Pragmatism Unbound (Harvard University Press, 2007). Sobre seu hegelianismo e desenvolvimentismo, ver meu Unger: Brasil, Democracia, Filosofia, em Pragmatismo Romântico e Democracia, de Tiago Medeiros Araújo, Edufba, 2016.
} 
e relativista (Rorty). Entretanto, ambos reivindicando igualmente o pragmatismo, a democracia e a virada linguística da filosofia, em suas versões analítica e pós-analítica (Wittgenstein e a desdogmatização progressiva, linguística, do empirismo analítico). Mas também em sua versão continental, propriamente hermenêutica, aquela da linguagem como reveladora de mundo. Ambos por fim coincidindo na noção (não metafísica, não transcendentalizada) de verdade como justificação à audiência concernida, envolvida nisso, porém, alguma idealização universalista - em Habermas, mas não em Rorty. ${ }^{5}$

É significativo que, no debate entre eles, não só Jürgen Habermas tenha-se assumido expressamente como pragmatista, e até considere que integra uma família pragmatista específica, kantiana, que incluiria outros da mesma espécie, como Hilary Putnam, mas também que critique Rorty como menos pragmatista do que ele, por não recuperar o que Habermas chama de intuições realistas do mundo da vida, exigidas pela prática cotidiana. Além dessa medida de realismo, o pragmatismo de Habermas preocupa-se em reivindicar incondicionalidade e universalidade para suas pretensões justificacionistas de validade/verdade, enquanto o pragmatismo de Rorty prefere abrir mão delas para colher o que lhe parecem ser benefícios do lado da efetividade prática, mas também da novidade e da criação, sua tinta romântica, nietzschiana, acreditando Rorty que verdade como justificação e persuasão - para uma comunidade progressivamente mais aberta, mas ainda assim particular, de algum modo ainda "sua" - já seria o suficiente e o melhor para exorcizar recaídas num "anything goes" relativista, em violências e exclusões no campo dos negócios humanos, que ainda nos ameaçariam.

Ambos, Habermas e Rorty, são ainda, conjuntamente, adversários da "razão centrada no sujeito" e do "paradigma da filosofia da consciência". E, por tudo isso, concebem uma mudança considerável no papel tradicional da filosofia - em Rorty, quase seu fim, pelo menos para a filosofia com F maiúsculo, como ele diz. Para Habermas, de "juíza transcendental” do resto da cultura, a filosofia passaria agora a partícipe interna a essa, no papel apenas de mediadora entre saberes especializados, e entre esses e o mundo da vida, embora mantendo-se além disso como guardiã da racionalidade. Já para Rorty a filosofia pode agora assumir-se como intervenção transformadora na cultura (mas sem papel transcendental, privilegiado), no sentido prioritário da conversação, da tolerância e da solidariedade (nomes melhores para a racionalidade), e, talvez ainda mais, no sentido da criação, essencialmente, de vocabulários e

\footnotetext{
${ }^{5}$ Ver meu (como organizador), Filosofia, Racionalidade, Democracia: Os debates Rorty-Habermas (São Paulo: Ed. Unesp, 2005), em particular minha introdução, da qual reelaboro aqui alguns trechos.
} 
redescrições. Não uma intervenção no sentido da verdade ou da objetividade, tomadas por Rorty como uma espécie de reminiscência, reificante, alienante, do paradigma da religião revelada, mas sobretudo associada à literatura e à poesia. Uma intervenção no sentido da imaginação e da poesia, aparentemente mesmo no caso do empenho por solidariedade.

Bem entendidos, os dois neo-pragmatismos, de Habermas e Rorty, têm pretensões a algo como transcendência de contexto, embora não do mesmo tipo. A de Habermas, kantiana, universalista, a de Rorty, romântica, imaginosa, particularista. E, bem entendidos, ambos se declaram anti-logocentristas, embora Rorty mais completamente. Ou seja, ambos atribuem prioridade à prática frente à teoria. Embora, como me parece, e aí está o ponto, seria melhor que o fizessem menos linguocentricamente, isto é, se tomassem prática como coisa mais encorpada e sensível, material. Não tão centralmente apenas como uso da linguagem, como se isso fosse o que tem supremo interesse epistemológico e prático-normativo, e constituísse o terreno prioritário e mais próprio da filosofia. Afinal de contas, como nos parece, a distância pode não ser tão grande entre linguocentrismo e logocentrismo.

Embora Habermas, quando distingue sua posição da de seu parceiro Karl-Otto Apel (que tem pretensão a uma "fundamentação normativa transcendental última", na prática discursiva, para a ética e a política democrática), pareça fazê-lo por concessões práticas, contextualistas, empiristas e destranscendentalizantes a Rorty, ele decididamente não está disposto a acompanhar Rorty até o fim numa empresa historicista, nominalista e naturalista (mas não de tipo reducionista/cientificista). Já Rorty, com pretensões de minar os alegados platonismos (e cartesianismos), remanescentes da filosofia e da cultura contemporâneas, alega que o que faz é apenas acompanhar Habermas até o fim na sua via de socialização da razão. Da razão como apenas disposição prática para o entendimento mútuo, para Rorty não universalista nem racionalista.

O fato é que Rorty, com sua virada intersubjetiva, social, da noção de racionalidade, virada que compartilha com Habermas, quer abrir mais espaço, do que o habermasismo concede, para um antiplatonismo. Não só para um quase-naturalismo, não-reducionista, destranscendentalizante, e para um contextualismo historicista. Mas também para uma radical contingência, do laço social e da própria individualidade, e, assim, para abrir mais espaço para uma invenção 'poética' (criativa, imaginosa, experimentalista) pública e para uma livre autocriação privada, única, aberta. Sem abrir mão da solidariedade, mas, ao contrário, colocando-a acima e no lugar da objetividade. Ou seja, pondo justificação no lugar de verdade e solidariedade no lugar de objetividade, mas também de universalidade. 
Tudo isso sustentado, como dizíamos, por via de um paradigma linguístico. Como nos parece, então, às custas do sensível, do reconhecimento do papel das coisas, às custas de um entendimento mais encorpado de prática e contexto, e mesmo de conhecimento. Disso parecendo decorrer uma redução, desencarnada e desmaterializante, até ascética, da experiência e da prática, tomada esta última essencialmente como prática linguística, como discursos, vocabulários, redesrições, comunicação. É por aí que Rorty e Habermas perigam resvalar para idealismos e relativismos, para agnosticismos e ceticismos (mais Rorty), para um discursivismo e uma noção idealista da sociedade como fórum (mais Habermas). Ainda que Rorty trate nisso tudo de ser mais anti-dualista, ao modo hegeliano, do que o kantiano Habermas, além de mais transformativo-criativista, a um modo pragmatista-nietzschiano. Enquanto Habermas, é verdade, mais realista (pela via de que dispõe), sem abrir mão de uma relação interna entre justificação e verdade, preocupa-se em resgatar as mencionadas intuições realistas do mundo da vida, a crença num mundo basicamente o mesmo para todos os usuários de linguagem, não obstante os seus diferentes modos particulares de encará-lo.

É em oposição a déficits decorrentes desse linguocentrismo que sugiro uma virada da prática discursiva para aquela ativa e sensível, envolvida com o mundo, e finalmente de praxis a poiesis, isto é, para a ação enquanto produtiva, também inevitavelmente sensível, envolvida com o mundo, com objetos, objetivações e apropriações. Isso por um ponto de vista pragmatista poiético, material, sensível, que pode ser aqui apresentado e desenvolvido em diálogo crítico com o de Marx (de cujo materialismo prático, instrumental, tanto Rorty como Habermas parecem querer fugir, como inevitavelmente "positivista" e "despótico"), como um retorno ao chamado paradigma da produção, devidamente reconstruído. Pois, além do mais, vale aproveitar que Marx é ainda muito popular, senão mesmo quase uma língua franca, entre tantos de nós acadêmicos latino-americanos. Embora em sua versão de materialismo Marx praticamente anule as noções de criação e autocriação enquanto propriamente inovadoras, indeterminadas e transcendentes de contexto. O fato é que Marx, como mais feuerbachiano e hegeliano, menos kantiano, mais envolvido com a nossa interação sensível com o mundo, converge, ademais, com intuições prático-sensíveis, ativistas, de alguns de nossos pensadores sociais da construção nacional e da cultura - educadores e ensaístas como os já mencionados. Esses, mais efetivamente modernistas e comprometidos com uma perspectiva de criação e autocriação, sensíveis, passíveis de recuperação filosófica entre nós. 


\section{Parte II - um novo retorno ao paradigma da produção (sem os problemas de Marx)}

Vejamos então Marx, a propósito de recuperar, em versão sensível, o melhor de Habermas e Rorty, isto é, de seus pragmatismos pós-metafísicos, históricos, contextualistas, anti-dogmáticos, não positivistas. Agora no interior de outro paradigma, do que chamo de ponto de vista poético-pragmático ou de materialismo pragmático-poiético, não linguocêntrico. Por um diálogo não apenas com o pragmatismo clássico, de onde podemos também colher fortes elementos não-linguocêntricos, não-idealistas, mas especialmente através de Marx e por aí também da Fenomenologia do Espírito de Hegel. Um diálogo - crítico - com o melhor de Marx como filósofo, que tenta uma conversão materialista de Hegel. Para um melhor retorno ao paradigma da produção, para além do neo-pragmatismo linguístico ou kantiano, tanto quanto de um realismo correspondentista e fundacionista.

Trata-se, em primeiro lugar, de abrir mão do que seriam seus (de Marx) dogmas teóricos bem pouco pragmáticos, antes especulativos (teoricistas, hegelianamente lógico-dialéticos, a priori, transcendentais, logocêntricos). Sobretudo, de Marx despido de seu essencialismo e de seu substancialismo. ${ }^{6}$ E dos dualismos e dicotomias, clássicos e modernos, platônicos e cartesianos, que apesar de tudo Marx reitera com muita força: essência vs. aparência, essência vs. existência, fundo vs. superfície, infraestrutura vs. superestrutura, ciência vs. consciência, sujeito vs. objeto, ideal vs. real. Pela retomada apenas do seu viés mais consequentemente materialista prático. Através das noções de práxis como produção sensível (poiesis), de nós e do social como atividade sensível e objetivação, e de um interesse pelo papel - relevante - dos meios materiais e de seus usos, na constituição de nossas relações e, portanto, de nós próprios. "O homem põe objetos porque é posto por objetos" - diz Marx nos Manuscritos de 1844, pretendendo corrigir o suposto elemento idealista subjetivo de Hegel, a propósito da Fenomenologia do Espírito como história da construção, pelos seres humanos, de si mesmos e do mundo. ${ }^{7}$ Aquele "porque" - na fórmula marxiana - deixando entrever, entretanto, um questionável apassivamento ou determinação causal que Marx apesar de tudo propõe para a ação humana.

De toda maneira, pode-se encontrar em Marx, bem entendido, como um ponto de vista prático consequente gostaria, elementos para uma particular superação, embora incompleta e contraditória, do mentalismo cartesiano, bem como do empirismo dogmático, intuicionista-

\footnotetext{
${ }^{6}$ Ver sobre isso por exemplo meu "Marx and Feuerbachian Essence", em The New Hegelians (D. Moggach, org.), Cambridge University Press, 2006.

${ }^{7}$ Sobre isso, ver, de Marx, Crítica da Dialética e da Filosofia de Hegel em Geral, seção 11 do $3^{\circ}$. dos Manuscritos Econômicos e Filosóficos, ou Manuscritos de 1844, de Marx.
} 
passivo, contemplativo (cf. $1^{\mathrm{a}}$. tese ad Feuerbach). De superação do ponto de vista do observador, bem como do ponto de vista idealista subjetivo e mesmo intersubjetivo, construcionista, que desconhece a produção sensível. De superação da ficção do indivíduo inteiramente dissociado de suas relações sociais, bem como do mundo e do sujeito como estáticos e totalmente exteriores um ao outro. Por fim, pode-se encontrar a sugestão de uma noção de ponto de vista (Standpunkt) material, social, que pode ser com proveito oposta aos perspectivismos subjetivistas, idealistas, relativistas, do paradigma linguístico de nossos dias, v.g. Rorty e Habermas.

O que chamo de embrião de um materialismo prático-normativo, poiético, não teoricista nem essencialista, em Marx, pode ser lido como compreendendo uns tantos "momentos" que se interpenetram, encontrados no conjunto de sua obra, porém aqui extraídos sobretudo das “Teses ad Feuerbach” (mas não só), por mais resumidas que essas sejam. ${ }^{8} \mathrm{O}$ ponto de vista materialista prático que Marx apresenta aí compreende:

1) Uma recusa do "empirismo dogmático", intuicionista-passivo, mentalista-cartesiano, contemplativo, que Marx chama de materialismo anterior, não constitutivamente prático , bem como uma rejeição do idealismo subjetivo que desconheceria a verdadeira atividade humana enquanto sensível, o trabalho;

2) Logo, uma superação da concepção - dualista - do mundo e do sujeito humanos como estáticos, exteriores um ao outro, tanto quanto como pensamento. E, logo, possivelmente, um abandono do ponto-de-vista do espectador e da fixação objetivista-representacionista do real, tanto quanto do idealismo subjetivo;

3) Uma desqualificação do indivíduo abstrato da percepção empirista, pré-social, da ficção do indivíduo como dissociado do conjunto das suas relações sociais e de uma forma social de vida determinada - não obstante sua (de Marx) essencialização/redução daquelas relações todas a uma única e determinante, coisa que não queremos seguir;

4) A já mencionada concepção de nós como seres que põem objetos e são postos por objetos (dos Manuscritos de 1844 até $O$ Capital), mas aqui dispensada de um elemento da formulação originária, aparentemente determinista, causal, de Marx: "porque são postos por objetos". Formulação em certa medida contraditória no próprio Marx, que tem problemas com a ideia de criação do novo como não causalmente inscrito num largo condicionamento precedente, no seu materialismo histórico. Isso, não obstante, no $O$ Capital, na caracterização

\footnotetext{
${ }^{8}$ As "Teses ad Feuerbach", de Marx, ou “Teses sobre Feuerbach”, de 1845, são geralmente publicadas em conjunto com a Ideologia Alemã, obra de Marx e Engels, do mesmo período. Elas foram consideradas por Engels como o genial embrião (em cerca de duas páginas) da sua genial concepção materialista histórica e econômica inteira.
} 
do trabalho humano em geral, Marx parecer reservar para ele um elemento de imaginação e de transcendência. ${ }^{9}$

5) Tudo isso atravessado por uma sugestão de epistemologia social e política, i.e. por uma ideia de congruência de pontos-de-vista filosóficos (epistemológicos, ontológicos e políticos) com posições sociais (Standpunkten) enquanto situações práticas materiais, lugares, no interior da sociedade. Atravessado, assim, por um contextualismo sensível, a que Marx, entretanto, parece não ser inteiramente fiel ele próprio, quando se trata de suas próprias concepções (correspondentistas em sentido cartesiano).

6) Ao final, para além desses elementos pragmatistas poiéticos, Marx, especulativamente, apresenta sua crítica do real social como ao mesmo tempo essencialmente cindido e atomizado, pelas "más" relações e práticas sociais imperantes (desiguais e conflitivas, em vez de cooperativas e comunistas), o que para ele acarretaria o desdobramento/duplicação do mundo também na religião, na filosofia, na ideologia - na alienação e no fetichismo (no $O$ Capital).

7) Para isso, Marx empenha-se em deduzir do cristianismo, isto é, da sua "tradução" feuerbachiana em humanismo comunitarista, anti-individualista do "ser-genérico" (Gattungswesen), sua noção-fundamento para crítica da sociedade, da economia política e da cultura. Isto é, “o homem” como um ser-genérico, cooperativo, "humanizado!”, como tal um valor, um fundamento normativo supostamente mundano, mas também essencializado, o homem como essência-genérica e, nesses termos, o novo Ser Supremo para os homens - como Marx mesmo diz.

8) É esse homem social-social que, introduzido na economia política pela noção de trabalho como inteiramente social, determinará, por necessidade, o rumo da supressão prática da contradição social e a restauração (reconciliação) da unidade-solidariedade social, com o fim da suposta auto-alienação do homem. Isso então abrindo caminho, para além do ponto-de-vista "egoísta" da Sociedade Civil de hoje, para o da Sociedade Humana de amanhã, o Socialismo e o Comunismo - para a necessidade e o imperativo de sua realização.

9) Do lado de seus elementos menos práticos, registremos ainda que Marx: a) distingue e hierarquiza dois níveis de prática: aquela egoísta, suja, judaica, a prática comum dos homens comuns na vida civil vs. a prática virtuosa, revolucionária, teoricamente iluminada (ver a primeira Tese); b) envolve-se, contraditoriamente, com uma variação da posição mentalista-

\footnotetext{
${ }^{9}$ Isso no volume I de $O$ Capital, no conhecido trecho em que Marx alega que o pior arquiteto é melhor do que a melhor abelha porque é capaz de conceber antecipadamente, na imaginação, a casa que constrói.
} 
correspondentista, quando, após afirmar que é a existência (prática, relacional, ativa) que determina a consciência, invoca a metáfora da câmara escura (correspondentista / inversora) na sua crítica ao idealismo e à ideologia (na Ideologia Alemã), e sobretudo defende o conhecimento científico como a espelhar / reproduzir na mente individual o movimento totalizante do real, por via da rearticulação dos dados objetivos sensíveis, mundanos, factuais, pelas categorias da lógica hegeliana em versão alegadamente materialista (ver a famosa Introdução de 1857, de Marx).

10) Finalmente, como já indicado, Marx sustenta um normativismo transcendentalista dogmático para seu ponto de vista social crítico, seja a partir de uma tradução feuerbachiana, humanista-comunitarista, naturalista, dos predicados/valores do Cristianismo (do Ser Supremo alienado), infinitizados, seja pela alegada demonstração do caráter, de fundo, essencial, inescapavelmente social, do trabalho, na sua crítica da economia política, um caráter alegadamente invisível, para seus atores, ao nível da enganadora superfície, como aparência real (cf. O Capital, vol. I).

\section{Parte III - o materialismo poiético-pragmático como alternativa}

O que pode resultar, pois, de nossa correção crítica e prática de Marx é ainda uma compreensão que trate de partir, mais ou menos como ele, de nosso emaranhamento prático sensível, produtivo, objetual, artefatual, com o mundo, de um pragmatismo poiético e um holismo prático-material.

Tomemos agora como ponto de partido o que chamo de nosso emaranhamento prático sensível criativo com o mundo, um emaranhamento produtivo - também cognitivo, estético, ético, político etc. Isso como base para um materialismo prático-poiético, que põe em estreita relação, de maneira renovada, homem, realidade, ação, conhecimento etc. de um modo que deve ao mesmo tempo distinguir-se tanto de certo realismo empirista representacionista, entendido por nós como pouco interessante para a realização das disposições livres, práticocriadoras dos seres humanos, quanto de um anti-representacionismo meramente linguístico, o de Habermas ou de o Rorty. Que tem preocupações semelhantes às nossas, mas tomado aqui como insuficientemente aberto à criação material sensível, embora disposto à crítica antipositivista e antiautoritária, e ao reconhecimento da dimensão social, não-fundacionsta, daquele emaranhamento.

Trato de alcançar esse ponto de vista, que considero mais fecundo, pela via de uma combinação de não-representacionismo prático e materialismo poiético, aqui sugerida como 
possivelmente mais apropriada às nossas circunstâncias e necessidades. E busco isso por recurso à utilização de sete noções principais:

a) uma noção de intencionalidade prático-sensível, significadora, como nosso modo básico de envolvimento com o mundo, como nossa iniciativa deliberada de dirigirmo-nos ativamente às coisas, tomá-las assim ou assado, dando-lhes assim significados. E assim, por esse trato com o mundo, formando delas noções (práticas) "antes" de qualquer recurso à linguagem, ainda que noções socialmente sustentadas, sedimentadas e compartilhadas - por práticas, inclusive linguísticas;

b) essa noção de intencionalidade constitui-se numa recuperação, aqui no seu nível mais elementar, de uma noção não-metafísica e não-dualista de autoconsciência, como uma dimensão eminentemente ativa, criadora, transcendentora, dos seres humanos. Que é o que Marx, contraditoriamente, empenha-se em aniquilar por sua crítica fundante e onipresente da noção de consciência;

c) uma noção de ação humana como ubiquamente e eminentemente poiésis, fazer criador que introduz coisas e modos no mundo, que põe o próprio mundo e que nos faz históricos;

d) uma noção de objetivação de conhecimento e imaginação, na ação, pelo homem, no mundo e nas coisas, algo como o espírito objetivo de Hegel, e que ecoa a noção de inteligência geral de Marx;

e) assim, uma noção de realidade humana como "subjetiva", não objetiva em sentido tradicional, independente, cartesiano; uma noção de realidade e de nós próprios como atividade sensível e como artefato - para além do que já propõe Marx;

f) as noções de normatividade e de significação como constituídas, não em primeiro lugar pela linguagem, mas pela nossa própria prática de lidar experimentalmente com mundo e coisas, orientada por nossos propósitos e interesses, e apoiada e permanentemente modificada pela introdução de objetos;

g) isso em oposição à ideia de uma normatividade 1) deduzida, de modo fundacionista, dogmática, da religião, 2) lida para dentro da realidade, por uma teoria da história e uma filosofia da economia, ou mesmo, finalmente, 3) postulada por um universalismo abstrato, de tipo kantiano;

Assim chegamos a uma concepção prática, holista-materialista, objetual, do mundo, da cultura e de nós mesmos, segundo a qual os seres humanos permanentemente põem/criam novos objetos (artefatos), sendo por sua vez - eles, indivíduos humanos em sociedade - postos/ 
constituídos/criados por tais objetos (artefatos) e pelas práticas/relações que tais objetivos permanentemente engendram e às quais dão suporte. Chegamos assim à concepção da sociedade como um conjunto de práticas, envolvidas com a reprodução, uso e/ou criação de objetos e objetivações. Tornando-se tais práticas igualmente nossas objetivações, que têm nos objetos seu suporte e que envolvem relações nas quais esses têm papel constitutivo. Tais práticas estão implicadas tanto na reposição/reprodução da sociedade quanto no desenvolvimento de novas coisas, novas relações e mesmo novas práticas, e portanto na modificação do mundo e de nós próprios. Esse seria possivelmente um dos espaços privilegiados de ação transformadora do mundo, e não alguma prática concebida como transcendente a tudo isso.

Parafraseando Marx, a dialética desse novo materialismo ficaria assim: na criação e no uso de objetos, os seres humanos desenvolvem entre si relações múltiplas e cambiantes, enquanto desenvolvem novas práticas e produzem novos objetos, artefatos, coisas e mesmo práticas. A criação de novas práticas, objetos e usos enseja - ou força - novas relações e novas formas de subjetividade entre os seres humanos, constituindo um mundo nosso, constituindonos a nós próprios como pertencentes a tal mundo, e constituindo assim o que chamamos de uma forma de vida, de um mundo, e o que chamamos de história. Não há por que supor que tal dialética só se dê na produção de bens ditos materiais, sem espírito, "na base" da sociedade, pelo uso de grandes meios de produção. E não na prática geral dos seres humanos de criar, usar e reproduzir, como inevitavelmente entrelaçados entre si, objetos, ideias, práticas, vocabulários, instituições - todos eles, enfim, artefatos - e de produzirem-se a si próprios como artefatos.

Nesse caso, deve cair o dualismo infraestrutura-superestrutura, não havendo por que entender que há pensamento privilegiadamente (embora irrelevantemente) no nível da superestrutura, mas não no da infraestrutura e em suas práticas consideradas produtoras em sentido estrito. Nem há por que entender que sejam nos dois casos pensamentos de ordens inteiramente diferentes (compreensivo vs instrumental), para além de uma terceira forma, absolutamente distinta, de pensamento, a Ciência, superior, transcendental (como a própria Teoria de Marx). Ao contrário, o pensamento sempre é, em todos os casos, o que se produz na e para a ação, como aquilo que orienta a conduta ou corresponde a ela e a acompanha.

Tanto em Marx, contraditoriamente, como no pragmatismo, tacitamente, haveria na verdade uma alegada congruência entre ponto de vista filosófico geral (como o pragmatismo e o materialismo histórico), seu contexto e suas consequências políticas e sociais. No primeiro, o comunismo como sociedade humana e desenvolvimento de um novo homem, plenamente 
social. No segundo, a democracia como forma de vida e de florescimento humano. Para o nosso caso, nosso ponto de vista poético-pragmático dá suporte a uma noção materialista prática de cidadania como empoderamento criativo por capacidades e meios, sem que isso implique necessariamente em consequências coletivistas ou liberais individualistas. Nem numa sociedade achatada, nem estatizada nem oligopolizada. Trata-se no nosso caso de um ponto de vista eminentemente civil.

A sociedade como forma de vida, como vimos, pode ser entendida como um agregado de práticas reprodutoras e produtoras, suportadas por objetos e constituindo objetivações, nas quais as relações entre pessoas e com o mundo decorrem de sua introdução por nós mesmos, por nossa imaginação e cálculo, e nos fazem quem somos - em permanente mudança. Numa sociedade assim compreendida podemos entender de um modo novo a relevância e o papel das chamadas forças produtivas, das relações que essas propiciam, cobram ou condicionam, que as possam favorecer ou limitar e entrar em conflito com elas, em benefício de relações novas. Forças produtivas que compreendem em primeiro lugar os indivíduos humanos como criadores, com suas potências, competências e recursos. Vale registrar ainda que as relações com os objetos podem determinar dissimetrias, como relações desequilibradas de poder, propriedade e competência.

Por essa via pode-se constituir e sustentar uma noção de cidadania material, produtiva, econômica, não passiva, protagonista, realizadora. Ficando então a democracia como uma forma de vida material e produtiva, envolvendo um empoderamento de todos por competências e meios. Aí onde estão as práticas de reposição da sociedade, numa forma de vida como conjunto de práticas de sua reprodução podem-se então desenvolver e efetivamente se desenvolvem suas práticas de transformação. Estamos assim de volta à associação de progresso e democracia ao avanço, difusão e democratização, de competências, recursos e capacidades (ou forças) produtivas também objetivadas em práticas, artefatos e instituições. Pelo que eu chamaria de uma proposta de democratização econômica, material, produtiva, da sociedade. Menos inclinada a admitir práticas como transcendentais e de uma natureza totalmente outra, em detrimento das comuns, como de natureza degrada. Isso, sim, seria um ponto de vista eminentemente civil. 